\title{
A simple in vitro technique to measure the release of endogenous dopamine and dihydroxyphenylacetic acid from striatal tissue using high performance liquid chromatography with electrochemical detection
}

\author{
Jill B. Becker, Edward Castañeda, Terry E. Robinson and Mary E. Beer \\ Department of Psychology and Neuroscience Laboratory Building. The University of Michigan, \\ Ann Arbor, MI 48109 (U.S.A.)
}

(Received November 161h, 1983)

(Revised March 1st, 1984)

(Accepted April 10th, 1984)

Key words: dopamine release - striatum - amphetamine - DOPAC - superfusion system - endogenous neurotransmitter release - dopamine

An easily constructed, inexpensive and simple system is described for the superfusion of neural tissue. To characterize the system, the dynamics of endogenous dopamine and dihydroxyphenylacetic acid release from striatal tissue were studied before and after exposure to potassium, amphetamine or cocaine.

\section{Introduction}

In vitro superfusion systems for studying endogenous neurotransmitter release, rather than radiolabelled transmitter release, have many advantages over other methods (Becker and Ramirez, 1980; Mulder, 1982). Unfortunately, endogenous transmitter release is not commonly measured, perhaps in part due to the considerable experience, manual dexterity, and patience required to operate previous systems (Becker and Ramirez, 1980). We report here a simple chamber design that can be inexpensively constructed from materials readily available in most laboratories. Eight of these chambers can be simultaneously operated with ease, and technical problems are minimal with proper maintenance. Significant changes from the previously reported methods (Becker and Ramirez, 1980) in the size of the chamber

Correspondence: J.B. Becker, Neuroscience Laboratory Building, 1103 E. Huron St., Ann Arbor, MI 48104-1687, U.S.A. 
and in the superfusion medium required that a series of experiments be conducted to characterize striatal dopamine (DA) release using this system.

\section{Methods}

\section{Superfusion medium}

A modified Krebs-Ringer phosphate medium with a final composition of: 120 $\mathrm{mM} \mathrm{NaCl}, 4.8 \mathrm{mM} \mathrm{KCl}, 1.25 \mathrm{mM} \mathrm{CaCl} \mathrm{Ca}_{2} \cdot 2 \mathrm{H}_{2} \mathrm{O}, 1.2 \mathrm{mM} \mathrm{MgSO}, 15 \mathrm{mM}$ phosphate buffer, $0.1 \%$ bovine serum albumin and $10 \mathrm{mM}$ D-glucose, was used in all experiments. When $60 \mathrm{mM}$ potassium $\left(\mathrm{K}^{+}\right)$was added to the medium the sodium concentration was reduced to $65 \mathrm{mM}$. When calcium was omitted from the medium sodium was increased to $121.2 \mathrm{mM}$. The medium was oxygenated by bubbling $95 \%$ $\mathrm{O}_{2}: 5 \% \mathrm{CO}_{2}$ through it for $15 \mathrm{~min}$ with continuous stirring. The $\mathrm{pH}$ of the medium was then adjusted to 7.4 .

\section{Tissue preparation}

Adult male Holtzman rats (Madison, Wisc.) were killed by decapitation and the brains removed. The right and left striata were dissected separately (see Becker and Ramirez, 1980) and placed in individual beakers of ice cold medium (maximum time $=2.5 \mathrm{~min}$ from decapitation to completion of the dissection). The tissue was then transferred to a glass Petri dish containing enough ice-cold medium to keep the tissue wet, and a razor blade was used to chop the tissue into approximately $1-\mathrm{mm}^{3}$ pieces. Each striatum was then placed into an individual superfusion chamber (Fig. 1) that contained medium warmed to $37^{\circ} \mathrm{C}$. At the conclusion of each superfusion. the tissue was removed from the chamber and weighed. The average amount of tissue in each chamber was $40.9 \pm 1.0 \mathrm{mg}(\mathrm{n}=83)$.

\section{Superfusion system}

The superfusion system is schematically represented in Fig. 1. The chambers (Fig. 1A) are constructed from 1-ml disposable allergist syringes (Becton-Dickinson, Rutherford, NJ). The barrel of each syringe is cut in cross-section producing a calibrated open tube $3.5 \mathrm{~cm}$ long. The bottom of the tube is sealed with the black stopper obtained from the syringe plunger (tip up) and a rubber cap. At the end of each superfusion the rubber cap can be removed and the black stopper used to gently push the tissue out the top of the chamber.

Medium is pumped through tygon tubing (Fig. 1B) by an 8-channel Technichron AutoAnalyzer Proportioning Pump at a rate of $100 \mu \mathrm{l} / \mathrm{min}$. The medium enters the chamber via a length of 18-gauge stainless steel hypodermic tubing that passes through a black stopper sealing the top of the chamber (also constructed from the end of a syringe plunger). The stainless steel tubing protrudes $8 \mathrm{~mm}$ from the stopper and is held in place by a dollop of solder (black oval in top stopper, Fig. 1A). The top stopper is positioned in the chamber so that the stainless steel tubing almost touches the bottom stopper. Medium exits the chamber from another length of stainless steel tubing located $10 \mathrm{~mm}$ above the bottom stopper, setting the volume 


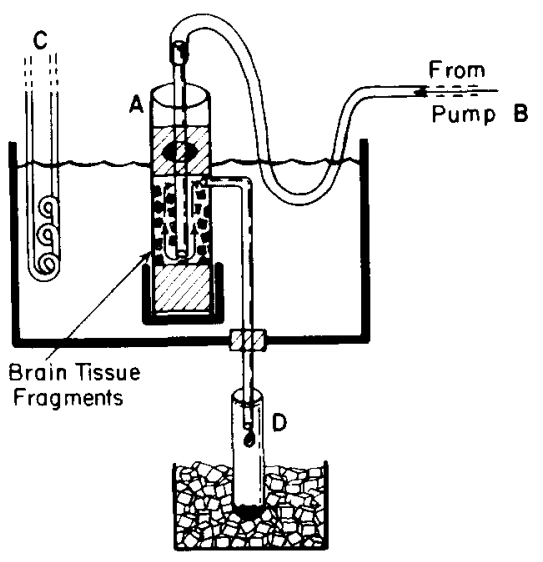

Fig. 1. The superfusion system. A: the superfusion chamber has a volume of $200 \mu \mathrm{l}$ and accommodates up to $50 \mathrm{mg}$ of brain tissue (see text for construction details). B: medium flows from the peristaltic pump through tygon tubing at $100 \mu \mathrm{l} / \mathrm{min}$. $\mathrm{C}$ : a circulating heater maintains the water bath temperature at $37^{\circ} \mathrm{C}$. The superfusion chamber is positioned in the water bath and the medium is warmed prior to entering the chamber by passing the tygon tubing through the warm water. Medium enters at the bottom of the chamber and exits at the top. $D$ : effluent samples are collected on ice in tubes that also contain $0.05 \mathrm{~N} \mathrm{HClO}_{4}$ and $\mathrm{DHBA}$ as an internal standard (see text for additional details).

in the chamber at $200 \mu \mathrm{l}$. This exit tubing makes a $90^{\circ}$ bend and then pierces a rubber plug located on the bottom of the water bath (Fig. 1D). The exit tubing is held in place by silicone adhesive liberally applied around the exit hole. It is also glued to a plastic ring that is constructed from the top of the syringe (not shown) that bridges the chamber wall and exit tubing near the bottom of the chamber. The day before each superfusion, the chamber is checked for any leaks in the seals and re-glued if necessary. In developing this chamber we tested many other designs that had the entrance and exit tubing located in a variety of configurations (e.g. medium entering the top and exiting the bottom or vice versa). A dye was pumped through the system in each case to determine how thoroughly the entering medium mixed with the medium in the chamber. With the design shown in Fig. 1 dye could be seen to mix with liquid throughout the chamber. In contrast, when the dye entered from a tube in the bottom and exited the top, it formed a channel of dye through the center and did not mix well with the surrounding liquid.

The medium in the chamber is warmed because the chambers are located in a water bath maintained at $37^{\circ} \mathrm{C}$ by a circulating heater (Fig. 1C). In addition, the tygon tubing passes through the water, warming the medium prior to entering the chamber. With this set-up we routinely use 8 chambers simultaneously.

In pilot experiments in, which sample collection started 25 min after the superfusion had begun, the spontaneous efflux of endogenous DA and DOPAC from striatal tissue decreased exponentially $(r=-0.967 \log$ time vs $\log$ DA release, $P<0.001 ; r=-0.968$ logtime vs $\log$ DOPAC release, $P<0.001)$. Therefore, sample collection began $1 \mathrm{~h}$ after the tissue was placed in the chambers when the spontaneous efflux of DA was approaching asymptote. Effluent was always collected on ice 
over 5 min intervals, in tubes containing $25 \mu \mathrm{l}$ of: $0.05 \mathrm{~N} \mathrm{HClO}_{4}, 1 \mu \mathrm{M}$ EDTA, 40 $\mu \mathrm{M} \mathrm{NaHSO}$ and $0.02 \%$ dihydroxybenzylamine (DHBA) as an internal standard. Samples were stored frozen at $-20^{\circ} \mathrm{C}$ for up to 4 days prior to being assayed.

The time required for the medium to reach the chambers from the inlet was calculated by recording the latency for an air bubble, introduced at the inlet. to reach the chamber. With this information, an experimental solution could be introduced by transferring the inlet ends of the tubing to a beaker containing the experimental solution (leaving a small air bubble to mark where the new solution began) at the appropriate time. At the end of the stimulation period, the tubing was returned to the beaker with normal medium, again marking with a small air bubble.

\section{Catecholamine assay}

DA and DOPAC concentrations in the effluent were measured by high performance liquid chromatography with electrochemical detection (HPLC-EC). Brownlee RP-18 (reverse phase, C-18, 5- $\mu \mathrm{m}$ particles) columns were used. The mobile phase was a $0.1 \mathrm{M}$ citrate-phosphate $(3: 2)$ buffer containing $0.1 \mathrm{mM}$ EDTA, methanol and sodium octyl sulfate with an apparent $\mathrm{pH}$ of 3.35. The amount of methanol varied from 6 to $15 \%$ and sodium octyl sulfate from 30 to $400 \mathrm{mg} / \mathrm{l}$, depending upon the column and its age. The electrochemical detector (LC-4A, BioAnalytical Systems, Lafayette, IN) employed a glassy carbon electrode with a potential of $+0.74 \mathrm{~V}$ against a $\mathrm{Ag} / \mathrm{AgCl}$ reference electrode. The detector sensitivity was set at $5 \mathrm{nA} / \mathrm{V}$. Under these conditions $20 \mu \mathrm{l}$ of the acidified effluent was injected (Rheodyne Injection Valve, Berkeley, CA) without further preparation. Standards of known concentrations of DA and DOPAC were prepared in the medium and a 4 point standard curve was obtained for each assay. The standard curve for DA was linear from 50 to $2000 \mathrm{pg}$, and for DOPAC from 50 to $1000 \mathrm{pg}$. All samples fell within these ranges (see Fig. 2). Endogenous DA and DOPAC release rates were expressed as $\mathrm{pg} / \mathrm{mg}$ tissue/min.

\section{$K^{+}$-stimulated release}

After the 1-h stabilization period baseline effluent samples were collected at $5 \mathrm{~min}$ intervals for $20 \mathrm{~min}$. Medium containing $60 \mathrm{mM} \mathrm{KCl}$ was then infused for $30 \mathrm{~s}, 1$ $\min , 2 \mathrm{~min}, 3 \mathrm{~min}, 4 \mathrm{~min}$ or $5 \mathrm{~min}(\mathrm{n}=4 /$ group) and 5 - $\mathrm{min}$ samples collected for an additional $20 \mathrm{~min}$. Due to the rapid mixing of $60 \mathrm{mM} \mathrm{KCl}$ with the contents of the chamber the effective concentration after a $30 \mathrm{~s}$ infusion duration was $20 \mathrm{mM} \mathrm{KCl}$ $(50 \mu \mathrm{l}$ of $60 \mathrm{mM} \mathrm{KCl}$ in a total volume of $150 \mu \mathrm{l}$, assuming tissue displacement of 50 $\mu l)$ and after $60 \mathrm{~s}$ infusion, the effective dose was $40 \mathrm{mM} \mathrm{KCl}$.

\section{Repeated $60 \mathrm{mM} \mathrm{K}^{+}$-stimulation}

To determine if striatal tissue retained its responsiveness following repeated stimulation, $60 \mathrm{mM} \mathrm{K}^{+}$was infused for $2.5 \mathrm{~min}$ at the beginning of the $5 \mathrm{th}$, $9 \mathrm{th}$ and 13 th 5 min intervals $(n=8$ superfusions).

\section{Amphetamine (AMPH)-stimulated release}

Effluent samples were collected for 145 -min intervals. Medium containing $10^{-7}$. 


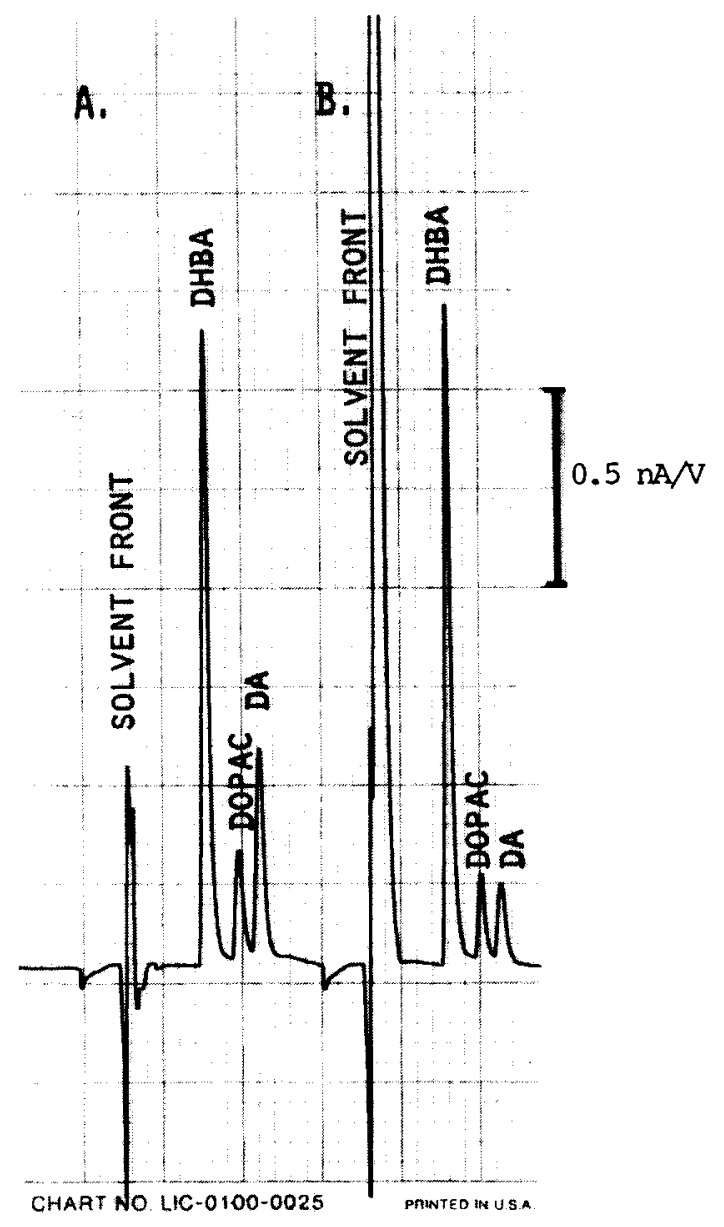

Fig. 2. Sample HPLC-EC chromatographs. A: standards of known concentrations were prepared in superfusion media. In this standard, a 20- $\mu$ l sample contained: $2 \mathrm{ng}$ DHBA (as an internal standard). 250 pg DOPAC and $500 \mathrm{pg}$ DA. B: a superfusion effluent sample obtained during the initial baseline period (after the 1-h stabilization period). Chromatographic conditions and methods given in the text, full-scale deflection was $5 \mathrm{nA} / \mathrm{V}$.

$10^{-6}, 10^{-5}, 10^{-4}$ or $10^{-3} \mathrm{M} \mathrm{AMPH}$ was infused for 1.0 or $2.5 \mathrm{~min}$ at the beginning of the 5 th interval. At the beginning of the 10 th interval $60 \mathrm{mM} \mathrm{K}^{+}$was infused for 2.5 min to determine if the tissue was still viable $(n=4-5$ superfusions/group).

\section{Calcium dependence}

To determine if AMPH and/or $\mathrm{K}^{+}$-stimulated DA or DOPAC release was calcium-dependent the right striatum was placed in normal medium $(n=4)$ and the left in calcium-free medium $(n=4)$. Following the 1 -h stabilization period samples were collected for twelve 5-min intervals. Medium containing $10^{-5} \mathrm{M}$ AMPH was infused for $2.5 \mathrm{~min}$ at the beginning of the 5 th interval, and medium containing 60 $\mathrm{mM} \mathrm{K} \mathrm{K}^{+}$infused for $2.5 \mathrm{~min}$ at the beginning of the 10 th interval. 


\section{Temperature dependence}

Superfusion chambers were positioned in an ice bath maintained at $0^{\circ} \mathrm{C}$ and the medium cooled to $0-4^{\circ} \mathrm{C}$. After $1 \mathrm{~h}$, samples were collected at 5 -min intervals. Medium containing $10^{-5} \mathrm{M} \mathrm{AMPH}$ was infused for $2.5 \mathrm{~min}$ at the beginning of the 5 th interval, and $60 \mathrm{mM} \mathrm{K}^{+}$infused for $2.5 \mathrm{~min}$ during the 10 th interval.

\section{Cocaine-stimulated release}

To determine if DOPAC efflux could be used as an index of DA reuptake. the effect of the DA reuptake blocker, cocaine, was tested. Following the $1 \mathrm{~h}$ stabilization period, samples were collected at 5 -min intervals. After 4 baseline samples, $10^{-4}$ $M$ cocaine was infused for $5 \min (n=5$ superfusions). The basal release rates of DA and DOPAC were compared with release during the interval in which cocaine was infused in to the chamber.

\section{Results}

Table I shows that, as expected, the longer the tissue was exposed to $\mathrm{K}^{+}$the more DA was released $\left(F_{5.18}=5.91, P<0.02\right)$. Interestingly, there was no relationship between the duration of exposure to $\mathrm{K}^{+}$and DOPAC efflux. Repeated depolarization of striatal tissue with $60 \mathrm{mM} \mathrm{K}^{+}$repeatedly stimulated the release of DA (Fig. $3 \mathrm{~A}$ ), without influencing DOPAC levels in the effluent (Fig. 3B).

AMPH stimulated the release of DA in a clear dose-related manner when infused for either $1 \mathrm{~min}\left(F_{4.18}=5.52, P<0.004\right)$ or for $2.5 \mathrm{~min}\left(F_{4.1 \mathrm{~K}}=9.74, P<0.001\right.$; see Fig. 4). In addition, $25 \mathrm{~min}$ after $\mathrm{AMPH}$ stimulation, the $\mathrm{K}^{+}$-stimulated release of DA was normal, with no influence of the preceeding dose of AMPH on the

\section{TABLE I}

THE MEAN ( \pm S.E.M.) AMOUNT OF ENDOGENOUS DA AND DOPAC RELEASED $(\mathrm{pg} / \mathrm{mg} / \mathrm{min}$ ) BEFORE AND AFTER THE INFUSION OF $60 \mathrm{mM} \mathrm{KCI} \mathrm{FOR} \mathrm{DIFFERENT} \mathrm{PERIODS} \mathrm{OF} \mathrm{TIME}$ $(\mathrm{n}=4$ SUPERFUSIONS/GROUP)

Basal release is the mean of effluent samples 3 and 4 , taken after the 1 - $h$ stabilization period, immediately before exposure to $60 \mathrm{mM} \mathrm{KCl} . \mathrm{K}^{+}$-stimulated release is the mean of effluent samples 5 and 6 , during and immediately after exposure to $60 \mathrm{mM} \mathrm{KCl}$.

\begin{tabular}{|c|c|c|c|c|}
\hline $\begin{array}{l}\text { Duration } \\
\text { of } 60 \mathrm{mM} \mathrm{K} \mathrm{K}^{+} \\
\text {infusion }\end{array}$ & $\begin{array}{l}\text { Basal } \\
\text { DA } \\
\text { release }\end{array}$ & $\begin{array}{l}\mathrm{K}^{+} \text {-stimulated } \\
\mathrm{DA} \\
\text { release }\end{array}$ & $\begin{array}{l}\text { Basal } \\
\text { DOPAC } \\
\text { release }\end{array}$ & $\begin{array}{l}\mathrm{K}^{+}-\text {stimulated } \\
\text { DOPAC } \\
\text { release }\end{array}$ \\
\hline $30 \mathrm{~s}$ & $15 \pm 2$ & $27 \pm 5$ & $8 \pm 1$ & $10 \pm 2$ \\
\hline $1 \mathrm{~min}$ & $19 \pm 4$ & $25 \pm 4$ & $10 \pm 4$ & $12 \pm 3$ \\
\hline $2 \mathrm{~min}$ & $13 \pm 3$ & $39 \pm 5^{* *}$ & $9 \pm 1$ & $10 \pm 1$ \\
\hline $3 \mathrm{~min}$ & $14 \pm 2$ & $54 \pm 16^{*}$ & $11 \pm 1$ & $12 \pm 2$ \\
\hline $4 \mathrm{~min}$ & $16 \pm 3$ & $63 \pm 8^{* *}$ & $12 \pm 1$ & $13 \pm 2$ \\
\hline 5 min & $14 \pm 1$ & $77 \pm 6^{* * *}$ & $13 \pm 2$ & $15 \pm 3$ \\
\hline
\end{tabular}

$\mathrm{K}^{+}$-stimulated release differs from basal release: ${ }^{*} P<0.07,{ }^{* *} P<0.02,{ }^{* * *} P<0.005$ (2-tailed paired t-test). 

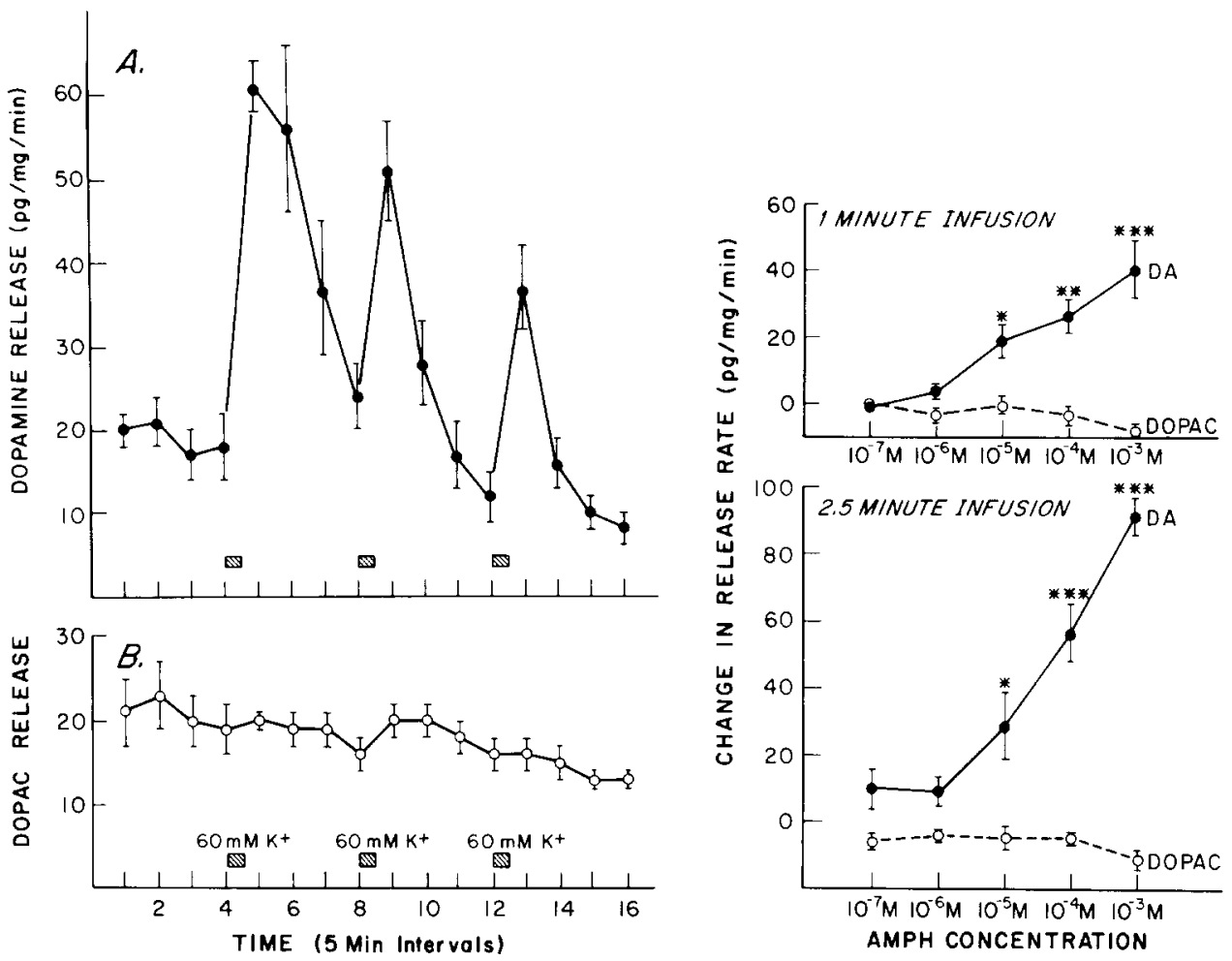

Fig. 3. Release ( $\mathrm{pg} / \mathrm{mg} / \mathrm{min})$ of endogenous DA (A) and DOPAC (B) from striatal tissue following repeated $\mathrm{K}^{+}$depolarization. Superfusion samples were collected over 5 min intervals. An infusion of 60 $\mathrm{mM} \mathrm{KCl}$ for $2.5 \mathrm{~min}$ (\$) began with the 5 th, 9 th and 13 th intervals of sample collection. Closed circles, mean DA release; open circles, mean DOPAC efflux. Bars indicate \pm S.E.M., $\mathrm{n}=8$ superfusions.

Fig. 4. The effects of varying the concentration of AMPH and the duration of AMPH infusion on the release of endogenous DA and DOPAC from striatal tissue. The change in release $\mathrm{rate}(\mathrm{pg} / \mathrm{mg} / \mathrm{min}$ ) is the mean of intervals 5-8 (the 20-min time period during and immediately following AMPH infusion) minus the mean of intervals $1-4$ (baseline release rate). Closed circles, mean change in DA release rate \pm S.E.M.; open circles, mean change in DOPAC release rate \pm S.E.M. Differs from baseline ${ }^{*} P<0.05$; ${ }^{* *} P<0.01 ;{ }^{* * *} P<0.005$.

subsequent response to $\mathrm{K}^{+}$. Again, there was no relationship between the dose of AMPH and DOPAC efflux $\left(F_{4.18}=2.5, P<0.08\right)$.

The basal rate of DA efflux was not $\mathrm{Ca}^{2+}$ or temperature-dependent (Fig. 5). As previously reported, we found that $\mathrm{K}^{+}$-stimulated DA release was both $\mathrm{Ca}^{2+}$ - and temperature-dependent, and that AMPH-stimulated DA release was temperature, but not $\mathrm{Ca}^{2+}$-dependent (Fig. 5). DOPAC levels in the effluent were not affected by $\mathrm{Ca}^{2+}$ or temperature.

The infusion of $10^{-4} \mathrm{M}$ cocaine increased DA concentrations in the effluent by $48.6 \pm 12.2 \%$ ( \pm S.E.M.) over baseline $\left(t_{4}=3.99, P<0.01\right.$, one-tailed), while simultaneously decreasing DOPAC concentrations by $12.2 \pm 5.5 \%\left(t_{4}=2.22, P<0.05\right.$, 


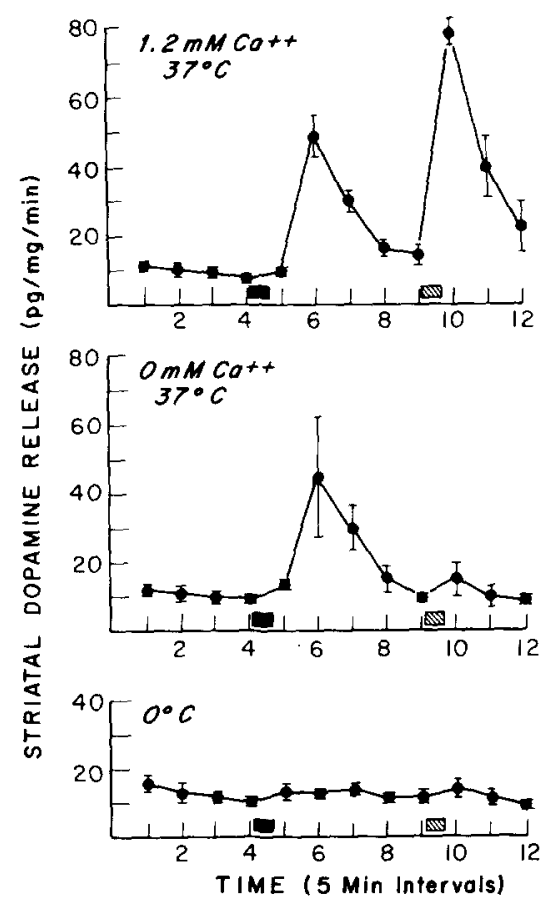

Fig. 5. Mean levels of AMPH- and $\mathrm{K}^{+}$-stimulated striatal DA release ( $\mathrm{pg} / \mathrm{mg} / \mathrm{min}$ ) with normal medium at $37^{\circ} \mathrm{C}$ (top), with calcium-free medium at $37^{\circ} \mathrm{C}$ (center), and with normal medium at $0^{\circ} \mathrm{C}$ (bottom). AMPH $\left(10^{-5} \mathrm{M}\right)$ was infused for $2.5 \mathrm{~min}$ at the beginning of the 5 th interval (a) and $60 \mathrm{mM} \mathrm{KCl} \mathrm{was}$ infused for $2.5 \mathrm{~min}$ at the beginning of the 10 th interval (W) in all superfusions. Bars indicate \pm S.E.M.

one-tailed). The increase in DA efflux was greater in magnitude than was the decrease in DOPAC efflux $\left(t_{4}=2.94, P<0.05\right.$, two-tailed $)$.

\section{Discussion}

An in vitro superfusion chamber is described that is simple and inexpensive to construct, and easy to operate. To validate the use of this system the release of endogenous DA and DOPAC from striatal tissue was studied. Consistent with previous reports (Meyerhoff and Kant, 1978; Becker and Ramirez, 1980; Schwarz et al., 1980; Wightman et al., 1981) it was found that: (1) $\mathrm{K}^{+}$-stimulated release of DA is dose-, calcium- and temperature-dependent; and (2) AMPH-stimulated release of DA is dose- and temperature-dependent, but calcium-independent.

A potential problem with many in vitro systems for measuring neurotransmitter release is that drug-induced increases in the concentration of DA in the medium could result from either increased DA release or decreased DA reuptake. In the system described here, the concentration of DOPAC in the effluent allows one to determine if an increase in DA concentrations is the result of decreased DA 
reuptake. This is because DOPAC is primarily formed intraneuronally following DA reuptake (Cubeddu et al., 1979; Delanoy et al., 1982). Therefore, if a drug blocks DA reuptake, the concentration of DOPAC would be expected to show a concomitant decline (Coyle and Snyder, 1969; Heikkila et al.. 1975; Cubeddu et al., 1979). We found that when reuptake was blocked with cocaine, there was a decrease in DOPAC efflux, but an even greater increase in DA efflux. We estimate that $57 \pm 20 \%$ of the increased DA in the effluent was not accounted for by the decrease in DOPAC efflux.

In this superfusion system a decline in DOPAC efflux may indicate that DA reuptake is blocked, but substantial increases in DA reuptake are prevented by the medium flow. $\mathrm{K}^{+}$-induced depolarization produced only a very small elevation in DOPAC efflux, and there was no relation between the duration of $\mathrm{K}^{+}$stimulation and the levels of DOPAC. In contrast, if released DA is not immediately removed. as in an incubation system, $\mathrm{K}^{+}$stimulation greatly increases the efflux of both DA and DOPAC (Delanoy et al., 1982). This indicates that the possible influence of DA reuptake on release is minimized with the superfusion system described here.

The mechanism by which AMPH increases DA concentrations extracellularly is not clearly understood and has been the subject of considerable speculation. The best available evidence suggests that AMPH primarily stimulates DA release, and that the reuptake blocking properties of AMPH are minimal (Heikkila et al., 1975; Moore, 1978; Fischer and Cho, 1979; Caviness et al., 1982). In the studies reported here there was a strong relationship between the concentration of AMPH in the medium and the increase in DA concentrations in the effluent. However, there was no relationship between the magnitude of the AMPH-induced decrease in DOPAC efflux and the dose of AMPH. This supports the idea that the reuptake blocking properties of AMPH are not the primary mechanism through which DA concentrations in the effluent are increased.

It should be noted that the medium used in these experiments did not contain a monoamine oxidase (MAO) inhibitor, ascorbic acid or tyrosine; 3 compounds frequently included (Meyerhoff and Kant, 1978; Becker and Ramirez, 1980; Wightman et al., 1981). In preliminary experiments we found that the inclusion of these agents (alone or in combination) did not affect the basal or AMPH-stimulated release of DA. However, DOPAC levels were dramatically decreased when a MAO inhibitor was included and increased when tyrosine was included. Because these agents did not facilitate the measurement of DA release, but clearly altered DA metabolism they were omitted from the medium.

The measurement of endogenous DA release avoids some of the potential problems with using radioactive tracers. For example, radioactive tracers may selectively label subcellular DA pools (Besson et al., 1969), that may or may not be the most physiologically relevant pools. In addition, if slices are used, radioactive tracers may not be uniformly distributed throughout the tissue because the preloaded neurotransmitter must diffuse through the tissue prior to uptake. The use of synaptosomes alleviates the diffusion problem, but presents other problems related to the integrity of the release mechanism(s) in synaptosomes (Mulder, 1982). Hopefully, the system described here will facilitate the use of superfusion systems for 
the measurement of endogenous DA and DOPAC release from the striatum to the extent that more researchers will consider the measurement of endogenous transmitter release over radiolabelled transmitter release.

\section{References}

Becker, J.B. and Ramirez, V.D. (1980) Dynamics of endogenous catecholamine release from brain fragments of male and female rats, Neuroendocrinology 31: 18-25.

Besson, M.J., Cheramy, A., Feltz, P. and Glowinski, J. (1969) Release of newly synthesized dopamine from dopamine containing terminals in the striatum of the rat. Proc. nat. Acad. Sci. U.S.A.. $62: 741-748$.

Caviness, J.N. and Wightman, R.M. (1982) Use of rapid superfusion to differentiate the release of dopamine from striatal tissue induced by sympathomimetic amines from release induced by potassium, J. Pharmacol. exp. Ther., 223: 90-96.

Coyle, J.E. and Snyder, S.H. (1969) Antiparkinsonian drugs: inhibition of dopamine uptake in the corpus striatum as a possible mechanism of action, Science, 166:899-901.

Cubeddu, L.X., Hoffmann, I.S. and Ferrari, G.B. (1979) Metabolism and efflux of $\left[{ }^{3} \mathrm{H}\right]$ dopamine in rat neostriatum: presynaptic origin of 3.4-[ $\left[{ }^{3} \mathrm{H}\right]$ dihydroxyphenylacetic acid. J. Pharmacol. exp. Ther., 209: $165-175$.

Delanoy, R.L., Hunter, G.D. and Dunn, A.J. (1982) Catecholamine metabolism in brain slices, Biochem. Pharmacol., 31: 3289-3296.

Fischer, J.F. and Cho, A.K. (1979) Chemical release of dopamine from striatal homogenates: evidence for an exchange diffusion model, J. Pharmacol. exp. Ther., 208: 203-209.

Heikkila, R.E., Orlansky, H. and Cohen, G. (1975) Studies on the distinction between uptake inhibition and release of $\left[{ }^{3} \mathrm{H}\right]$ dopamine in rat brain tissue slices, Biochem. Pharmacol, 24: 847-852.

Meyerhoff, J.L. and Kant, G.J. (1978) Release of endogenous dopamine from corpus striatum. Life Sci., 23: $1481-1486$.

Moore. K.E. (1978) Amphetamine: biochemical and behavioral actions in animals. In L.L. Iversen, S.D. Iversen and S.H. Snyder (Eds.), Handbook of Psychopharmacology, Vol. 11, Plenum Press, New York. pp. $41-98$.

Mulder, A.H. (1982) An overview of subcellular localization, release and termination of action of amine, amino acid, and peptide neurotransmitters in the central nervous system. In R.M. Buijs. P. Pevet and D.F. Swaab (Eds.), Chemical Transmission in the Brain. Progress in Brain Research, Vol. 55, Elsevier Biomedical Press, Amsterdam, pp. 135-155.

Schwarz, R.D., Uretsky, N.J. and Bianchine, J.R. (1980) The relationship between the stimulation of dopamine synthesis and release produced by amphetamine and high potassium in striatal slices, $J$. Neurochem., 35: 1120-1127.

Wightman, R.M., Bright, C.E. and Caviness, J.N. (1981) Direct measurement of the effect of potassium, calcium, veratridine and amphetamine on the rate of release of dopamine from superfused brain tissue, Life Sci., 28: 1279-1286. 